\title{
Implementation of a Web System to Detect Anemia in Children of Peru
}

\author{
Ricardo Leon Ayala, Noe Vicente Rosas, Laberiano Andrade-Arenas \\ Facultad de Ciencias e Ingeniería \\ Universidad de Ciencias y Humanidades \\ Lima, Perú
}

\begin{abstract}
Now-a-days, anemia is considered a worldwide problem that not only seriously affects our health, but also has economic and social consequences. Therefore, seeks to provide a solution to the problem to detect anemia with a non-invasive method quickly, simple and low-cost way. In this research work, a web system was designed applying the scrum methodology to detect anemia and simplify the detection process of anemia in Peruvian children. In addition, this study shows as a result a technological prototype that helped in the diagnosis of anemia ; at the same time it provides food recommendations to patients to combat anemia efficiently, with a variety of recipes and ingredients that are available in any home, helping in the recovery process. In addition, the analysis carried out on children with anemia in Peru is shown, where it is known that Puno is the most affected department. With respect to the capital Lima, the most affected district is Callao. However, this amount is expected to drop considerably in the coming years.
\end{abstract}

Keywords-Anemia; diagnosis; health; scrum; web system

\section{INTRODUCTION}

Anemia is considered today a global problem, which not only seriously affects health, but also has economic and social consequences. Anemia is characterized by a decrease in the level of red blood cells or by an abnormal reduction in hemoglobin of less than $11 \mathrm{~g} / \mathrm{dl}$ for children under 6 years of age and $12 \mathrm{~g} / \mathrm{dl}$ for children over 6 years of age [1]. Therefore, it is currently known that 2 billion people suffer from this disease worldwide [2].

A review of studies, conducted in 19 European countries, found that between 2 and 25 percent of children aged 6 to 12 months were iron deficient. In addition [3], preschool children in low- and middle-income countries are estimated to be anemia.

On the other hand, a diagnosis carried out on 112714 children, indicated that the low consumption of iron in food is one of the main causes of infant anemia in India. Since 80\% of children between 12 and 23 months had anemia and $69.5 \%$ of children under 5 years of age were anemics [4].

Peru, is no exception [5], since anemia in the country is mostly found in the low-income Andean regions, since several studies affirm that the population of approximately 463 districts has this disease, which is a major problem that threatens public health.

The Ministry of Health [6], published a report, indicating that 6 out of 10 children between 6 and 12 months of age have anemia, a worrying situation that requires further follow-up.
As we know, children are more prone to anemia, and this is due to iron deficiency, the same happens with children under 12 months, in premature infants anemia occurs in the first months of life [7]. In addition, it was identified that Puno, Pasco, Cusco, Loreto, Ucayali and Madre de Dios are the places most affected by anemia [8]. For this reason, this research work offers a viable solution to the problem of anemia, using a web system, in order to contribute to the reduction of the high percentage of anemia in Peru.

The proposed research, seeks to provide a solution to the problem, to detect anemia with a non-invasive method, in a fast, simple and low-cost way. It allows us to reduce the process of blood analysis, leaving aside the conventional invasive methods to measure hemoglobin levels and identify anemia. Thanks to the use of technology, anemic children under 8 years of age are easily recognized in Peru, thus reducing the impact of that disease on society and treating it at the earliest possible stage.

The objective of the research, is to design and develop a web-based system, applying the scrum methodology, to noninvasively detect and simplify the process of detecting anemia in children in Peru.

This research work is conformed as follows: Section II presents the Literature Review. Section III defines the methodology to be applied to the project and defines each stage in a theoretical way. Section IV describes the case study, Section V describes and shows the result and discussion obtained. Finally, Section VI defines the conclusion and future work.

\section{Literature REVIEW}

The problem of anemia in children is common today, both in Lima and in the province for different reasons. The different results, methodologies and limitations found in the different articles on anemia in children are analyzed below.

The application of expert systems is applied in different fields, such as the following article [9]. In it applied expert systems oriented to deep learning. Applying artificial intelligence and taking into account the best known models such as the neural network in the short and long term. They carried out the prediction by collecting information to perform the training of the model, in addition, this information helped them to discover more accurate patterns. To demonstrate the effectiveness of the predictive model, they applied this knowledge in the field of air pollution and power generation. In both cases the prediction had a high success rate when comparing the results with real data. 
On the other hand, according to research [10], indicates that the development of a non-invasive mobile application based on the pulse oximetry method and the use of a sensor, based on oxygen saturation values and hemoglobin concentration, can detect anemia in children, facilitating and benefiting the low-income population, since parents who suspect that their children may have anemia, have to submit them to clinical examinations, which are usually expensive and require specialized equipment. Adding to this, the vast majority of children with this disease are in rural areas with few resources, which makes it a bit complicated to have enough money to carry out the corresponding tests.

In other words [11], the creation of a mobile application and the use of additional tools would help to simplify the process of diagnosing anemia in an easy, simple and non-invasive way, making it accessible to anyone with no prior medical knowledge and low resources. However, in another research, another method is described to detect anemia in a non-invasive way by incorporating an algorithm based on neural networks in the mobile application, to detect hemoglobin levels by simply taking pictures of the fingertips.

Similarly, in the following thesis [12], presented an app, that provides recommendations to reduce poor nutrition, in case of anemia, in children in the school "Apostle of Punchauca", the mobile application was developed in order to reduce cases of anemia, source of information for parents, in addition, to prevent future cases of anemia in children, which is why thanks to its application they were made aware of the risks of anemia, how to combat it and know how to identify it.

In the same way, another research, details that used a similar methodology as the previous author, highlighting that the development of the application, with an image analysis algorithm, that analyzes the color data and image metadata allows quantitative and non-invasive self-mea,surement of hemoglobin levels in the patient's blood with high accuracy without the need for any accessories or calibration equipment [13].

On the other hand, [14] also implements a server-side algorithm to process the collected data, employing machine learning algorithms, that are trained using deep learning concepts to enable it to publish accurate results by simply analyzing fingertip color. The author [2] considers that anemia is originated when the concentration of hemoglobin within the red blood cells it is below normal.

In conclusion, different research works have been studied with similar methods that have successfully achieved the proposed objectives. Thanks to this, can highlight that the use of algorithms allows a more accurate diagnosis to detect anemia with a non-invasive method, achieved with the help of technology allowing access to any person.

\section{Methodology}

The agile scrum methodology, was used for the elaboration of this research work. It is considered agile because it uses incremental and iterative process approaches. On the other hand, it has proven to be more useful than the traditional waterfall model, because it improves the productivity of the processes and helps to reduce the time consumed for its realization. In a traditional waterfall model, planning is done before testing, and the process is managed in phases and once it is done, it is not possible to go back to the previous phase. On the other hand, scrum can make changes at any stage to improve results [15]. The scrum flow is shown in Fig. 1.

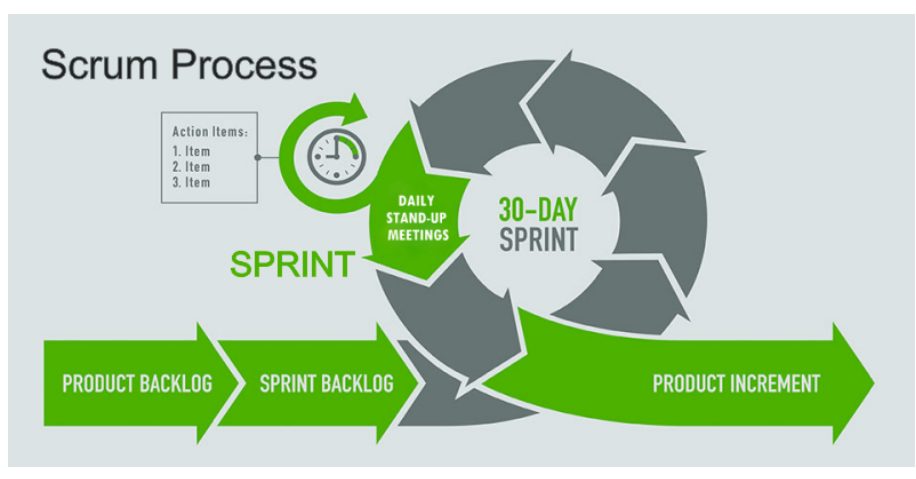

Fig. 1. Scrum Flow.

\section{A. Scrum}

The use of scrum involves integrating roles between teams, an advantage of using scrum is that it allows teams to adapt quickly to manage and plan their work, since each step of scrum allows you to plan, design, develop and test the code, all these activities are divided between the following roles [15]

\section{B. Scrum Practices}

Scrum has practices, also called Scrum formalities: Daily Meeting, Sprint Review, Sprint Planning Meetings and Sprint Retrospective [16]:

1) Daily Meeting: The meeting is held every day, where the team discusses the problems and the process of the project

2) Sprint Review: A meeting is held in which the team presents the results at the end of each Sprint to the owner.

3) Sprint Planning Meetings: A meeting is held to define the activities to be carried out during a Sprint.

4) Sprint Retrospective: A meeting is held to evaluate the team's unemployment during the Sprint and the practices to be carried out in order to improve team productivity.

\section{Scrum Development Structure}

1) Requirements Stage: It is established to obtain the planning requirements of the project.

2) Definition of User Stories: It is the description of the functionality of the system, for this the requirements are analyzed, in collaboration between the client and the team, the user stories will be improved throughout the life of the project.

3) User Stories Prioritization: The priority of each of the user stories [17], is established and the order in which they be developed is determined, taking into account which is the most fundamental for the project and thus following a hierarchy. 
4) Analogous Estimation: When the user stories are obtained, they go through an examination, where the use of a tool or an estimation method is required [18], this consists of a study of each of the user stories, referring to the time that the scrum team believes can develop it, in this phase involves both the time and the resources and expenses that may be needed.

5) Creation of the Product Backlog: User stories, priorities and required tasks are included in a Product Backlog. It includes the features or short and long term requirements and functionalities, that have been defined jointly by the development team and Product Owner, and also establishes the points or level of effort for each task. During the sprint process [19], the assigned tasks are movable depending on the requirements of the Product Owner.

6) Definition of Sprint Speed and History Points: The speed and time of development of each Sprint, is analyzed through an analysis that varies according to the experience of the Scrum team [20].

7) Sprint Presentation: The established Sprint is presented according to the requirements and the determined times, in this phase tests are performed on what is presented by the scrum team, being accepted or denied, this is repeated according to the number of sprint that contains a project.

8) Feedback: At the end of the project or each sprint, the scrum team, holds a feedback meeting, where they analyze everything developed in order to know their successes and failures in all aspects, in order to improve in the next project or sprint.

\section{Development Tools}

1) $C$ (Sharp) programming language: $\mathrm{C}$ is a modern programming language, based on the $\mathrm{c}++$ language and taking functions from other languages such as Java. The programming is mainly used object oriented. Currently it is still a language that is eating in the computer world and is mainly used for web development, software development and mobile applications [21].

2) ASP.NET Technology: ASP.NET technology, is a program architecture created on the basis of several programming languages, developed by Microsoft Corporation. In comparison with other developed models [22], ASP.NET stands out for having tools that help the programmer. In addition, has a high-level interactive graphical interface, a large customization layer, easy operation and high efficiency, when executing development processes, such as: creation of dynamic web pages. In addition ASP.NET incorporates servers, request, responsive pages, etc. In this way, it facilitates the development of a web. That is why, in the present research work ASP.NET was used for the development of a web site.

3) Microsoft Visual Studio: It is a modern development environment, which can be used to create programs, applications and software components for Microsoft Windows. Using object-oriented promotion, the program text consists of a set of descriptions of components when certain events occur. It uses the principles of component inheritance, which allows the creation of properties, events and methods [23]. The concept of Visual programming is implemented in the Visual Studio environment with the help of Windows.

\section{TABLE I. USER STORIES}

\begin{tabular}{|c|l|}
\hline $\mathrm{N}^{\circ}$ & \multicolumn{1}{|c|}{ User Stories } \\
\hline H1 & $\begin{array}{l}\text { I as a user want the Web System to allow me to log in with my } \\
\text { Gmail, Outlook or other alternatives to have a more convenient } \\
\text { access. }\end{array}$ \\
\hline H2 & $\begin{array}{l}\text { As a user, I want the Web System to allow me to register my } \\
\text { personal data to have access to all the functionalities. }\end{array}$ \\
\hline H3 & $\begin{array}{l}\text { As a user, I want the Web System to inform me how to perform } \\
\text { the test in order to have an assertive diagnosis. }\end{array}$ \\
\hline H4 & $\begin{array}{l}\text { I as a user want the Web System to allow me to perform a test } \\
\text { to diagnose my status. }\end{array}$ \\
\hline H5 & $\begin{array}{l}\text { As a user, I want the Web System to allow me to perform the } \\
\text { diagnosis through my own photos in order to obtain a more } \\
\text { efficient result. }\end{array}$ \\
\hline H6 & $\begin{array}{l}\text { As a user I want the Web System to provide me with the } \\
\text { statistics and results according to my diagnosis to know why the } \\
\text { diagnosis has been positive or negative. }\end{array}$ \\
\hline H7 & $\begin{array}{l}\text { As a user, I want the Web System to provide me with dietary } \\
\text { recommendations, diets and information based on my diagnosis } \\
\text { to improve my current condition. }\end{array}$ \\
\hline H9 & $\begin{array}{l}\text { I as a user want the Web System to have a selective food section } \\
\text { according to my preferences in order to get personalized } \\
\text { recommendations. }\end{array}$ \\
\hline H10 & $\begin{array}{l}\text { I as a user want the Web System to show a section of recipes } \\
\text { with high nutritional level to strengthen my hemoglobin level. }\end{array}$ \\
$\begin{array}{l}\text { I as a user would like the Web System to allow me to provide } \\
\text { feedback and comments on the recipes to inform the } \\
\text { effectiveness of each recipe. }\end{array}$ \\
\hline
\end{tabular}

4) Balsamiq: Balsamiq mockup,is one of the software tools used for design or prototyping, also to develop the user interface of an application. Balsamiq Mockup [24],[25], makes it easy to create the user interface, by providing you with the necessary tools to facilitate the creation of the application design. That is why Balsamiq was used, for the creation of the research prototypes.

5) Development architecture: For the development of the application, both front-end and back-end tools are needed, that is why in Fig. 2, the development architecture is shown, in each section the tools to be used are listed.

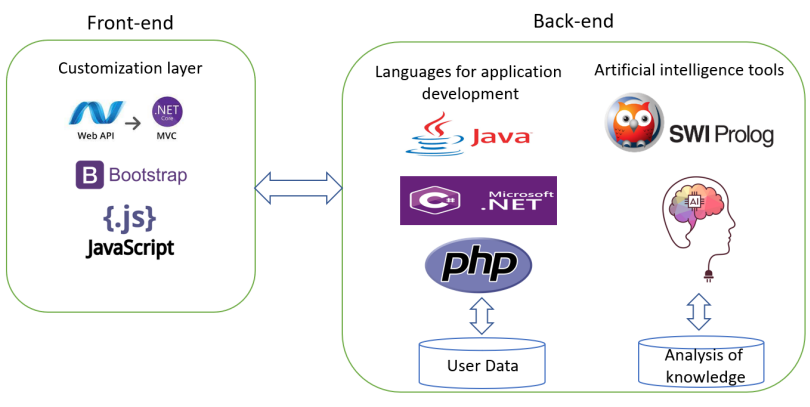

Fig. 2. Development Architecture Diagram.

\section{CASE STUDY}

\section{A. Start-up Stage}

1) User Stories: After knowing the functional requirements, user stories were created, which were defined based on the requirements, as shown in Table I.

\section{B. PLanning Stage}

1) Analogous Estimation: In this stage, the complexity estimation was made with respect to the development of each 
story, for this, the qualification range goes from 1 to 13,1 is the lowest complexity level and 13 is the highest. To make the estimation, $\mathrm{H} 1$ and $\mathrm{H} 2$ are taken as a base, since this is where the "Login" is developed, so as an example, H3 is located in column 2, which indicates that $\mathrm{H} 3$ is 2 times more complex to develop than $\mathrm{H} 1$ and $\mathrm{H} 2$, the same logic applies to the other stories. Thanks to the Analogous Estimation, it is possible to present an idea about the functional development of each story for a future project. To arrive at the following result, the team discusses the estimation of each story and classifies them according to criteria. As shown in Table II.

TABLE II. AnAlogous Estimate

\begin{tabular}{|l|l|l|l|l|l|l|}
\hline & 1 & 2 & 3 & 5 & 8 & 13 \\
\hline H1 & Login & & & & & \\
\hline H2 & Login & & & & & \\
\hline H3 & & 2 Login & & & & \\
\hline H4 & & & & & 8 Login & \\
\hline H5 & & & & & & 13 Login \\
\hline H6 & & & & 5 Login & & \\
\hline H7 & & & 3 Login & & & \\
\hline H8 & & & & 5 Login & & \\
\hline H9 & & & & 5 Login & & \\
\hline H10 & & 2 Login & & & & \\
\hline
\end{tabular}

2) Creation of the Product Backlog: For the creation of the complete backlog, it was ordered according to its history, priority and estimation. This information is obtained from the analog estimation table and the prioritization of the user stories. Table III, shows the Product Backlog.

3) Sprint Speed Definition and History Points: o carry out the following chart, it was decided together with the development team, to divide the sprint into four, in addition to detailing which user stories belong to each sprint. For example, $\mathrm{H} 1, \mathrm{H} 2$ and $\mathrm{H} 3$ belong to sprint 1 . As shown in Fig. 3, sprint 1 has 4 points, this result was obtained thanks to the information of the analog estimation table, where the effort points obtained by the stories were added, $\mathrm{H} 1$ and $\mathrm{H} 2$ obtained 1 point each and $\mathrm{H} 3$ obtained 2 points, the sums of these stories belonging to the first sprint gives us as a result 4 points. sprint velocity refers to the estimated time for the completion of a sprint, the velocity is determined by the development team. In total, there are 45 points of history and an average of 30 points of speed.

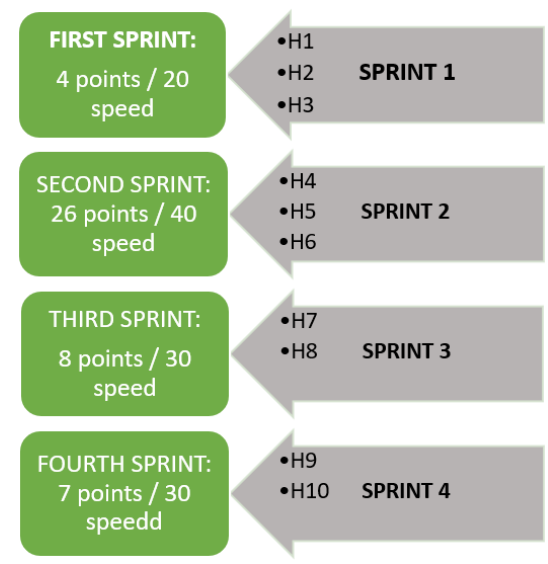

Fig. 3. History and Speed Points.
TABLE III. PRODUCT BACKLOG

\begin{tabular}{|l|l|l|}
\hline User Stories & Priority & Estimation \\
\hline $\begin{array}{l}\text { H1: As a user, I want the Web System } \\
\text { to allow me to log in with my Gmail, } \\
\text { Outlook or other alternative accounts to } \\
\text { have a more convenient access.. }\end{array}$ & 1 & 1 \\
\hline $\begin{array}{l}\text { H2: As a user, I want the Web System } \\
\text { to allow me to register my personal data } \\
\text { to have access to all the functionalities. }\end{array}$ & 2 & 1 \\
\hline $\begin{array}{l}\text { H3: As a user, I want the Web System } \\
\text { to inform me how to perform the test in } \\
\text { order to have an assertive diagnosis. }\end{array}$ & 3 & 2 \\
\hline $\begin{array}{l}\text { H4: I, as a user, want the Web System to } \\
\text { allow me to perform a test to diagnose } \\
\text { my status. }\end{array}$ & 4 & 8 \\
\hline $\begin{array}{l}\text { H5: As a user, I want the Web System } \\
\text { to allow me to perform the diagnosis } \\
\text { through my own photos in order to } \\
\text { obtain a more efficient result. }\end{array}$ & 5 & 13 \\
\hline $\begin{array}{l}\text { H6: As a user, I want the Web System } \\
\text { to provide me with statistics and results } \\
\text { according to my diagnosis to know why } \\
\text { the diagnosis has been positive or neg- } \\
\text { ative. }\end{array}$ & 6 & \\
\hline $\begin{array}{l}\text { H7: As a user, I want the Web System } \\
\text { to provide me with dietary recommen- } \\
\text { dations, diets and information based on } \\
\text { my diagnosis to improve my current } \\
\text { condition. }\end{array}$ & 7 & 5 \\
\hline $\begin{array}{l}\text { H8: I, as a user, want the Web System to } \\
\text { have a selective food section according } \\
\text { to my preferences in order to get per- } \\
\text { sonalized recommendations. }\end{array}$ & 8 & \\
\hline $\begin{array}{l}\text { H9: I, as a user, want the Web Sys- } \\
\text { tem to show a section of recipes with } \\
\text { high nutritional level to strengthen my } \\
\text { hemoglobin level. }\end{array}$ & 9 & \\
\hline $\begin{array}{l}\text { H10: I, as a user, want the Web System } \\
\text { to allow me to provide feedback and } \\
\text { comments on the recipes to inform the } \\
\text { effectiveness of each recipe. }\end{array}$ & 10 & \\
\hline
\end{tabular}

IV shows the duration of each Sprint, as well as the estimated time to develop each functionality.

TABLE IV. SPRINT BACKLOG

\begin{tabular}{|l|l|}
\hline Interface & Duration \\
\hline Web system to detect anemia & 4 months \\
\hline Sprint 1: Login Interface & 1 week \\
\hline Sprint 1: Registration Interface & 1 week \\
\hline Sprint 1: Home Interface & 2 week \\
\hline Sprint 2: Input evaluation & 2 weeks \\
\hline Sprint 2: Creation of activities & 2 weeks \\
\hline $\begin{array}{l}\text { sprint 2: Creation of interac- } \\
\text { tive games }\end{array}$ & 2 weeks \\
\hline $\begin{array}{l}\text { Sprint 3: Activity customiza- } \\
\text { tion features }\end{array}$ & 2 weeks \\
\hline $\begin{array}{l}\text { Sprint 3: Interactive game } \\
\text { customization features }\end{array}$ & 2 weeks \\
\hline Sprint 4: Results reports & 2 weeks \\
\hline
\end{tabular}

\section{RESULT AND Discussion}

\section{A. Development of Prototypes by user Stories}

1) Sprint Presentation: In this stage of development, the prototypes of the web page are shown, ordered according to the sprint and its estimation. Each image specifies which story it belongs to and the criteria they have had for the creation of the design.

- $\quad$ First Sprint: As shown in Fig. 3, the first sprint has a

The estimated duration of the project is 4 months, Table 
total of 4 points, which include $\mathrm{H} 1, \mathrm{H} 2$ and $\mathrm{H} 3$, the design of each of them will be shown below.

H1: As a user, I want the Web System to allow me to $\log$ in with my Gmail account, Outlook or other alternatives to have a more convenient access.

For Story 1 we show the page where the user can log in, plus you have the option to register using your Gmail or Facebook account. It was decided to split the structure of the page in order to focus the user's attention to the form. this is shown in Fig. 4.

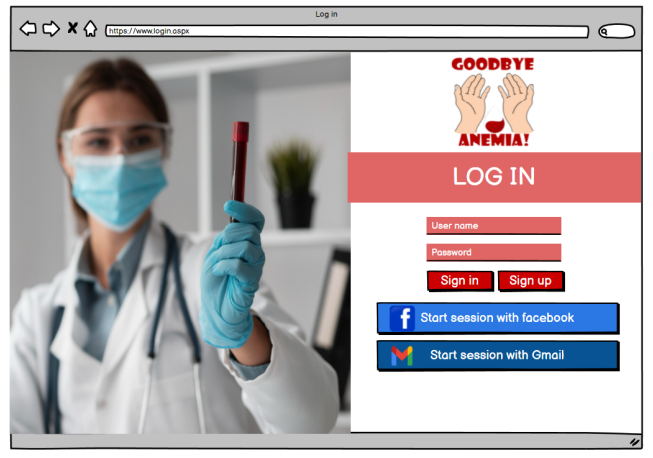

Fig. 4. Start of Session.

H2: As a user, I want the Web System to allow me to register my personal data to have access to all functionalities. Fig. 5 shows the user registration form in case you do not have a user name and password. The data requested are basic but necessary to access the system's functionalities.

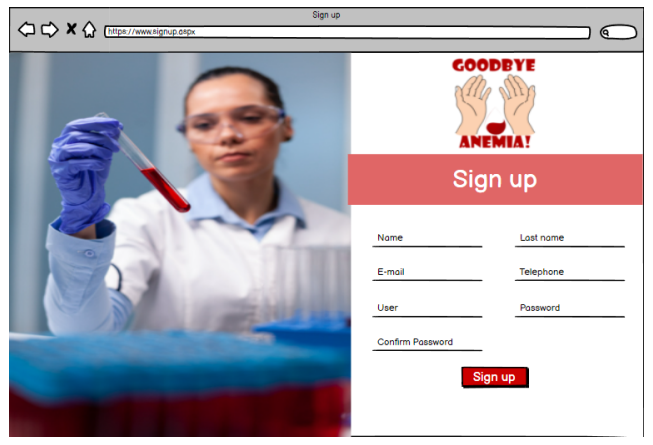

Fig. 5. Registration.

Fig. 6 shows, the main page, in the menu there is a button that takes you to the diagnostic test. Continuing with the content of the page, it has a section where it includes the "Informative Guide", this button will take you to the previous guide to perform the diagnosis.

H3: As a user, I want the Web System to inform me how to take the test in order to have an assertive diagnosis. A guide is shown in Fig. 7, which was designed for the user to follow and take into account the recommendations before performing the test, in order to avoid errors during the test.

\section{Second Sprint:}

It consists of a total of 26 story points, which is a

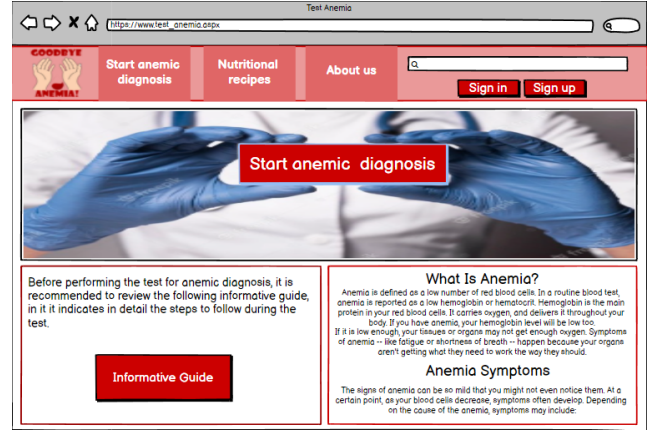

Fig. 6. Home Page.

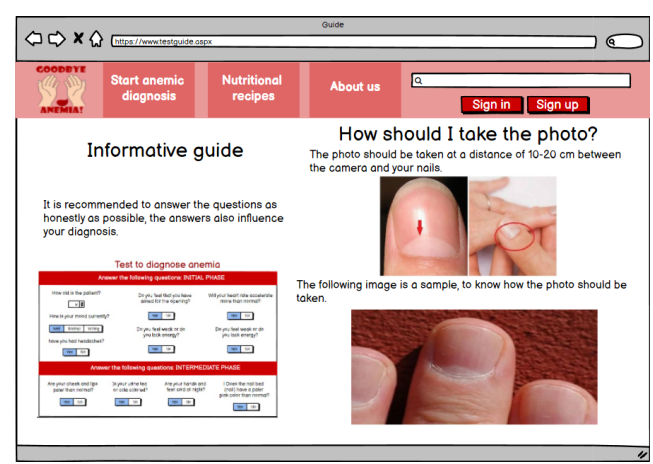

Fig. 7. Informative Guide

more complex indication for system development and prototyping. The design of each story is shown below. H4: I, as a user, want the Web System to allow me to perform a test to diagnose my status. The test design is shown in Fig. 8. The test is developed in two stages, the first stage consists of answering various questions necessary for the diagnosis.

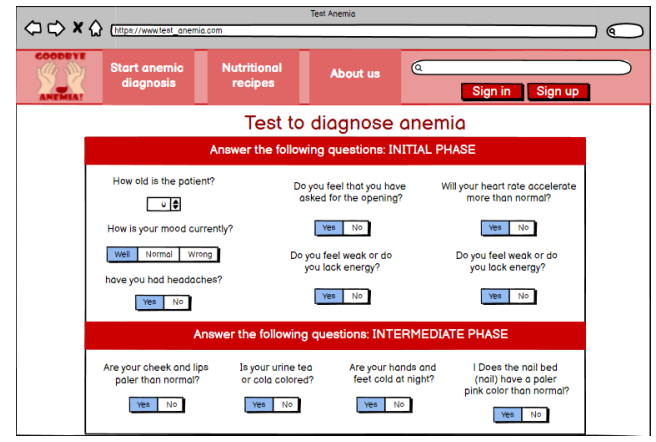

Fig. 8. Diagnostic Test.

H5: As a user, I want the Web System to allow me to perform the diagnosis through my own photos in order to obtain a more efficient result. After having carried out a previous questionnaire, the next section allows us to upload a photo of the patient's nails. upload a photo of the patient's nails, in this way with the help of artificial intelligence the application will detect, based on the color of the nails, whether anemia is present, this analysis directly influences the final diagnosis. All 
this is shown in Fig. 9.

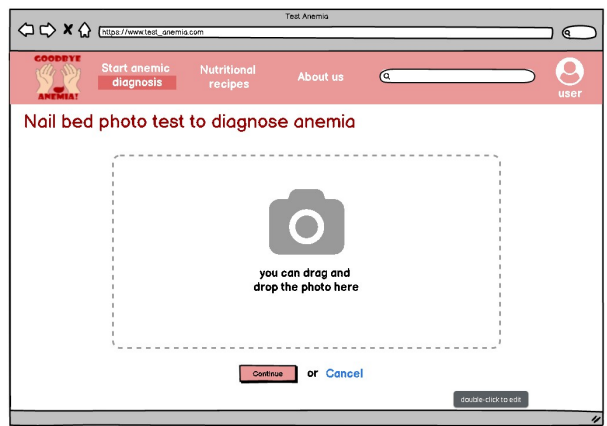

Fig. 9. Photo Diagnostic Test

H6: As a user, I want the Web System to provide me with statistics and results according to my diagnosis to know why the diagnosis has been positive or negative. As shown in Fig. 10, the results of the diagnosis are shown in the following bar graph: on the $\mathrm{x}$-axis is the result of the questions and on the y-axis is the maximum score. It should be added that it shows the result "Negative" or "Positive", this result varies depending on the patient's diagnosis. The Recommendations section will be discussed later.

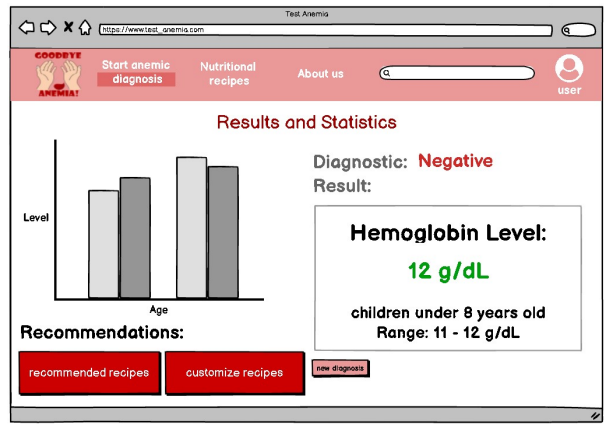

Fig. 10. Diagnostic Results Table.

Third Sprint:

H7: As a user, I want the Web System to provide me with dietary recommendations, diets and information based on my diagnosis to improve my current condition. The recommendations section is shown in Fig. 10, however this section is shown in Fig. 11.

H8: As a user, I want the Web System to have a selective food section according to my preferences to obtain personalized recommendations. As shown in Fig. 11, in the recommendations section, the patient has the possibility to select the foods of his or her preference, this information will later be displayed in a section of recipes, which include these previously selected foods in order to personalize the patient's food in a certain way.

Fourth Sprint:

H9: I, as a user, want the Web System to show a section of recipes with high nutritional level to strengthen my hemoglobin level. As shown in Fig.

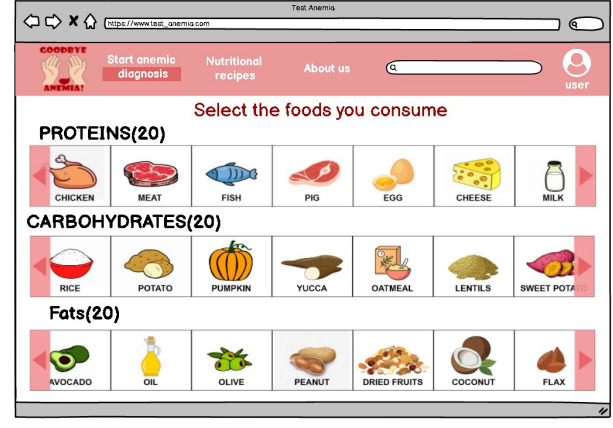

Fig. 11. Selective Food Section.

12, the web system has a recipe section, where the patient has the possibility of choosing the recipes of preference, and also where the recipes are displayed with the foods chosen in Fig. 11.

H10: I, as a user, want the Web System to allow me to give feedback and comments on the recipes to inform about the effectiveness of each recipe. Finally, in Fig. 12 , the patient can rate the recipe using star points ranging from 1 to 5 , as well as make a comment on the recipe in order to help or motivate future patients to try the recipes.

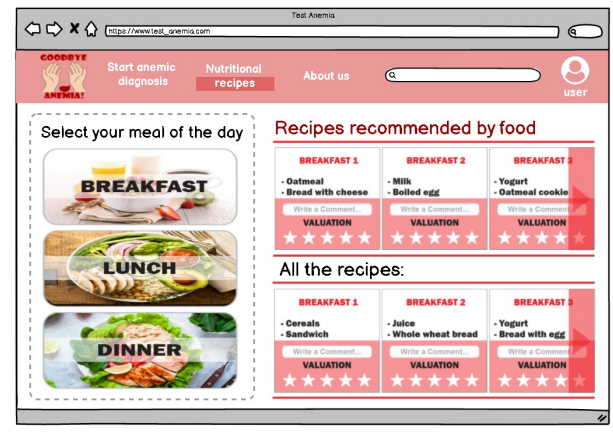

Fig. 12. List of Recipes to Combat Anemia.

\section{B. Survey Conducted for the Creation of user Stories}

For the development of the requirements, a survey was conducted among 40 people, including fathers and mothers in Lima-Peru. The survey was conducted with the help of the Google Forms tool. The questions were formulated with the purpose of knowing the user's preferences. Likewise, the answers were limited to the conditional "true" and "false". Table V, below shows the questions asked to the respondents.

1) Survey Analysis: According to the survey, it was obtained, the following results, which helped us to define the list of requirements, for the development of the web system, that will allow us to detect anemia and include some additional options that will help in the improvement of the patient as shown in Fig. 13.

- Of the 40 people surveyed, 32 opted to register before, accessing the website because it would give them a personalized profile and access to additional functions. 
TABLE V. QuEStions AsKed to RESPONDENTS

\begin{tabular}{|c|c|}
\hline $\mathrm{N}^{\circ}$ & Survey Questions \\
\hline 1 & Have you suffered from anemia? \\
\hline 2 & Have you ever used a website that detects anemia? \\
\hline 3 & $\begin{array}{l}\text { Would you like to enter directly to the website or do you want to } \\
\text { register? }\end{array}$ \\
\hline 4 & $\begin{array}{l}\text { Would you like the page to allow login with your account from } \\
\text { Gmail? }\end{array}$ \\
\hline 5 & $\begin{array}{l}\text { Would you like to carry out a previous survey related to your } \\
\text { current state of health? }\end{array}$ \\
\hline 6 & $\begin{array}{l}\text { Do you consider the implementation of AI (Artificial Intelligence) } \\
\text { necessary for the diagnosis? }\end{array}$ \\
\hline 7 & Would you like to show the results with graphs and tables? \\
\hline 8 & $\begin{array}{l}\text { Would you like the website to give you advice and recommendation } \\
\text { at the end of the diagnosis? }\end{array}$ \\
\hline 9 & Do you know foods that avoid suffering from iron deficiency? \\
\hline 10 & Do you know recipes to combat anemia? \\
\hline 11 & Would you like recipes to fight anemia included? \\
\hline
\end{tabular}

- On the other, hand 36 people would like to $\log$ in quickly, using their Gmail account for immediate access.

- 30 of them want to carry out a previous survey regarding, their current health status in order to have a more assertive diagnosis.

- In addition, 28 respondents who were aware of artificial intelligence, considered it necessary to incorporate it for a better diagnosis, offering them greater reliability of the results.

- 35 of the participants would like to be able to graphically, display the results for better understanding.

- On the other hand, respondents were asked if they would like to see the incorporation of advice and recommendations after a diagnosis, with the result that all respondents were in favor of incorporating those functionalities. Likewise, 38 of them would like to include recipes to combat anemia according to the results obtained in their diagnosis.

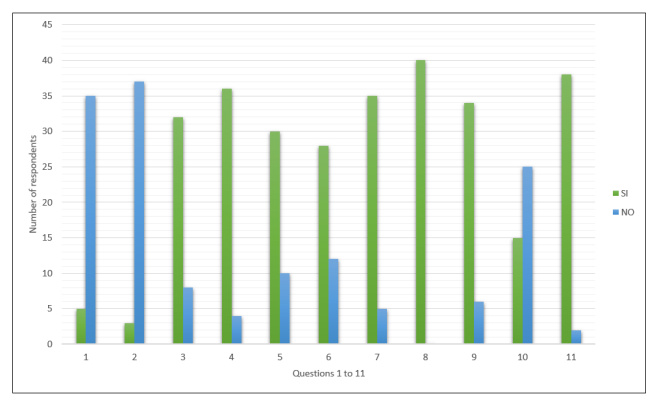

Fig. 13. Survey Results

\section{Analysis of each Sprint by Burndown Chart}

The use of Burndown chart, also called burndown diagram, represents graphically the effort and the follow-up of the tasks, during the established time of each sprint [26]. Generating the data graphically, the $\mathrm{x}$-axis of the Burndown chart shows the time set per sprint and the $y$-axis shows the history points. Moreover, the blue line represents the expected values and the orange line reflects the progress of the history points, the further away from the blue line the less incremental value has been added. In other words, user stories are not completed or advanced.

1) First Sprint: According to the results obtained, the first sprint is made up of 4 story points with a set time of 4 weeks. As can be seen in Fig. 14, during the first few days, the points were successfully advanced, but between the end of August and the beginning of September, this changed, delaying the proposed advances.

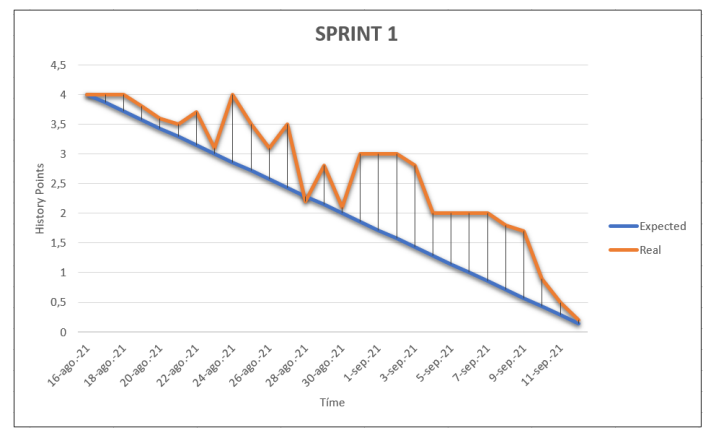

Fig. 14. Analysis of the First Sprint.

2) Second Sprint: It is made up of 26 story points, with a time frame of 6 weeks. During the development of the sprint we can observe that the advances in some days were completed on time and there were even early story deliverables as shown in Fig. 15.

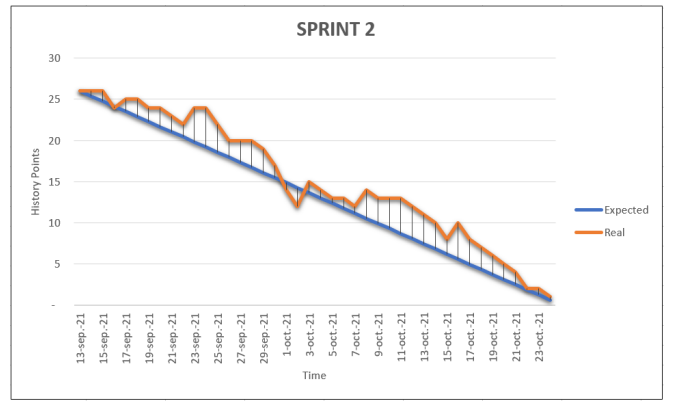

Fig. 15. Second Sprint Analysis.

3) Third Sprint: Composed of 8 story points, with a set time of 4 weeks, the development of the sprint was very good with all story points being completed starting with an early delivery and then with minimal delay with progress, but manageable as shown in Fig. 16.

4) Fourth Sprint: It has 7 story points, with a planned time of 2 weeks. Likewise, as in Sprint 3 the results were very parallel to the expected values demonstrating, a great development and performance of the sprint, culminating with the development of the web page for anemia diagnosis as shown in Fig. 17.

\section{Analysis of Children with Anemia in Peru}

1) Analysis in Peruvian Children: As shown in Fig. 18, the departments with the highest prevalence of anemia in children are the following: Puno, Loreto, Pasco, Huancavelica 


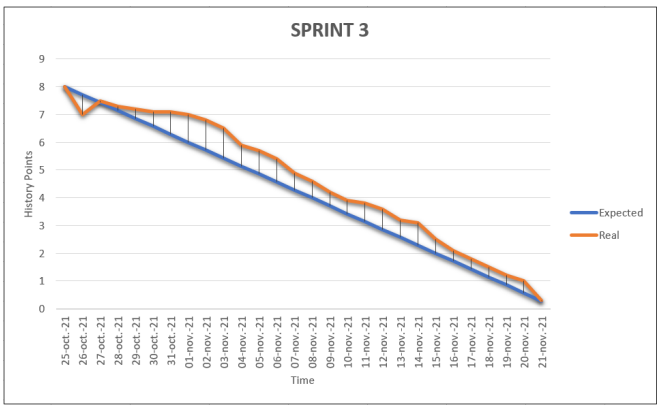

Fig. 16. Third Sprint Analysis.

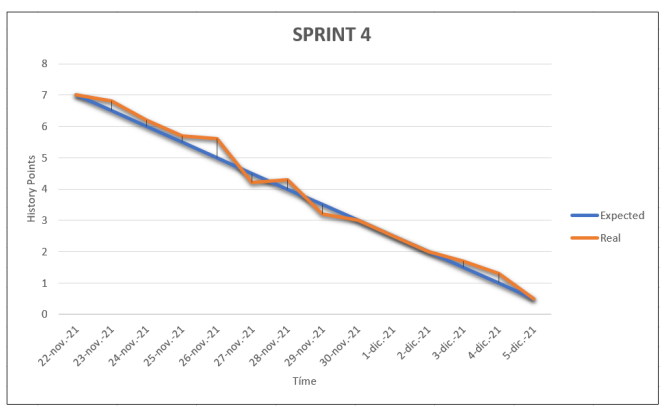

Fig. 17. Fourth Sprint Analysis.

and Ucayali. Thanks to this information, it was concluded that the first test carried out by the web system, be performed in these departments, since they are the most affected by this disease, and therefore, they should be attended as soon as possible. On the other hand, the departments with the lowest prevalence are: Lambayeque, Moquegua, La Libertad, Tacna, Lima and Cajamarca. Similarly, the Web System will be beneficial. However, it will not have the same impact as in the most affected departments. In Peru, practically $50 \%$ of the child population does not have a good control of their diet and this is reflected in the following graph. In short, our web system will present a solution to this problem and reduce these results to improve the quality of life of our Peruvian brothers and sisters.

\section{Current Situation of the Pandemic}

Prevalence of anemia in children aged 6 to 35 months, according to departments
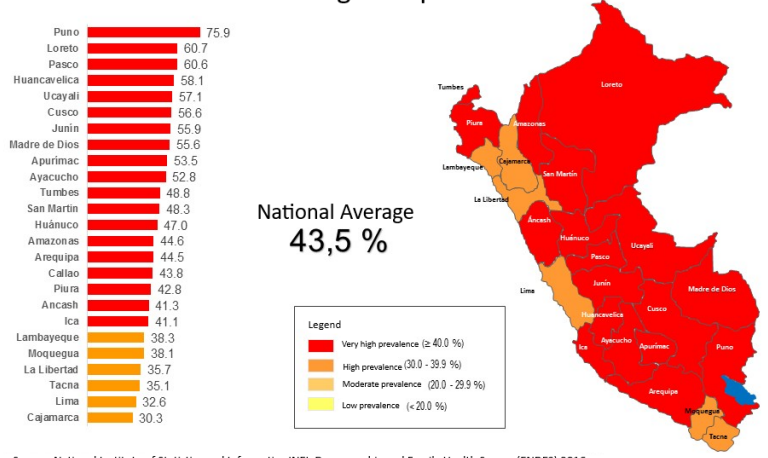

Fig. 18. Situation of Children with Anemia in Peru [27].
2) Analysis of Children in Callao: The district of Callao, has a high prevalence rate of anemia in children under 3 years of age. children under 3 years of age, which is why an in-depth analysis was carried out. As Fig. 19, the blue line represents the infection rate in Peru and the orange line represents Callao. and the orange line represents Callao. Thanks to the following analysis, it is known that, in 2021, only 2 out of every 10 children under 3 years of age will be affected by anemia, which is great news, given that years of This is great news, since years ago this result was alarmingly higher.

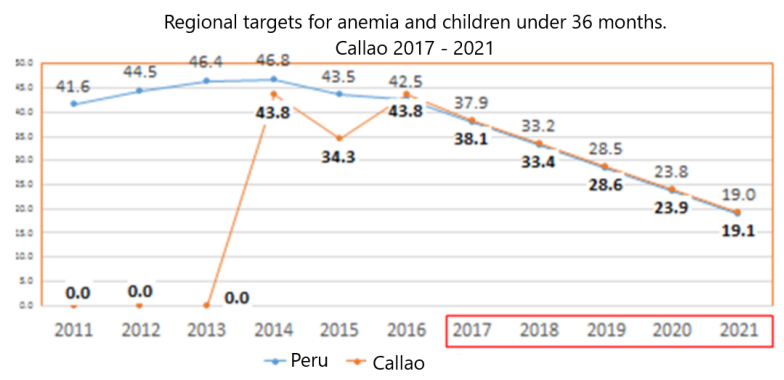

Fig. 19. Situation of Children with Anemia in Callao [27].

\section{CONCLUSION AND FUtURE WORK}

In conclusion, in this research work it was possible to design a web system to detect anemia in children, with the help of the design tool Balsamiq and applying the Scrum methodology. Thanks to Balsamiq it was possible to present the creative idea and the functionalities requested by the users through eye-catching and intuitive graphics.

With respect to the methodology, the Scrum framework was of vital importance, since it allowed a sequential development with high value, thus improving the quality of the product. In addition, the various charts and graphs that Scrum presents are key to presenting information clearly and accurately.

In the future, it is expected to complement this research by developing the web system, applying all the steps of this article to make this web system a reality. The development of the tool will be useful for people who do not have an adequate diet or feel they need an anemic diagnosis. This is why the implementation of the web system is expected as soon as possible, in order to contribute to the health sector and help people who require a diagnosis.

\section{ACKNOWLEDGMENT}

Recognize the University of Sciences and Humanities, and its research institute, for their support in research.

\section{REFERENCES}

[1] R. Prasanth, "Prevalence of Anemia in both Developing and Developed Countries around the World," World Journal of Anemia, vol. 1, no. 2, pp. 40-43, 2017.

[2] M. Cabanillas-Carbonell, H. Ñahuiña-Balbuena, J. Soto-Justiniano, and O. Casazola-Cruz, "Mobile application for the monitoring and control of the diet in people with anemia," in 2020 International Conference on $e$-Health and Bioengineering (EHB). IEEE, 2020, pp. 1-4.

[3] E. Mantadakis, E. Chatzimichael, and P. Zikidou, "Iron deficiency anemia in children residing in high and low-income countries: risk 
factors, prevention, diagnosis and therapy," Mediterranean Journal of Hematology and Infectious Diseases, vol. 12, no. 1, 2020.

[4] N. G. Onyeneho, B. C. Ozumba, and S. Subramanian, "Determinants of childhood anemia in india," Scientific reports, vol. 9, no. 1, pp. 1-7, 2019.

[5] A. Hernández-Vásquez, D. Azañedo, D. A. Antiporta, and S. Cortés, "Spatial analysis of gestational anemia in Peru, 2015," Revista Peruana de Medicina Experimental y Salud Publica, vol. 34, no. 1, pp. 43-51, 2015.

[6] A. Delgado and N. P. Ccancce, "Where is the highest rate of children with anemia in Peru? An answer using grey systems," International Journal of Advanced Computer Science and Applications, vol. 11, no. 5, pp. 313-317, 2020.

[7] J. Velásquez, Y. Rodríguez, M. Gonzáles, L. Astete, J. Loyola, W. Vigo, and Á. Rosas, "Factores asociados con la anemia en niños menores de tres años en Perú: análisis de la Encuesta Demográfica y de Salud Familiar, 2007-2013.revistaBiomédica[revista en inetrnet]2016[acceso 30 de septiembre];36;[220-9].http://dx.doi.org/10.7705/biomedica.v3," Biomédica, vol. 36, pp. 220-229, 2016.

[8] D. I. Garrido-Salazar, S. M. Garrido-Salazar, and G. Vivas-Armas, "Anemia frequency in children living at Andean high altitude in Ecuador, Peru, and Bolivia," Acta Pediatrica de Mexico, vol. 40, no. 6, pp. 305317,2019

[9] R. Ul Islam, M. S. Hossain, and K. Andersson, "A deep learning inspired belief rule-based expert system," IEEE Access, vol. 8, pp. 190637 $190651,2020$.

[10] R. P. Córdova Cárdenas, "Diseño e implementación de una aplicación móvil basada en android para la evaluación de anemia ferropénica en personas de acuerdo al nivel de hemoglobina," Ph.D. dissertation, 2018. [Online]. Available: http://dspace.uazuay.edu.ec/handle/datos/8173

[11] J. Jayakody, E. Edirisinghe, and S. Lokuliyana, "HemoSmart: A NonInvasive Device and Mobile App for Anemia Detection," Cognitive Engineering for Next Generation Computing, pp. 93-119, 2021.

[12] R. Bendezu and A. Ysla, "App de recomendaciones alimentarias para reducir la mala alimentación en casos de anemia en niños del colegio "apoóstol de Punchauca"," Tesis de pregrado, Universidad San Martin de Porres, 2020. [Online]. Available: https://hdl.handle.net/20.500.12727/6824

[13] R. G. Mannino, "A noninvasive, image-based smartphone app for diagnosing anemia," no. May, 2018.

[14] A. Hafeel, H. S. Fernando, M. Pravienth, S. Lokuliyana, N. Kayanthan, and A. Jayakody, "IoT Device to Detect Anemia: A Non-Invasive Approach with Multiple Inputs," 2019 International Conference on Advancements in Computing, ICAC 2019, pp. 392-397, 2019.

[15] W. Mahmood, N. Usmani, M. Ali, and S. Farooqui, "Benefits to organi- zations after migrating to Scrum," Proceedings of the 29th International Business Information Management Association Conference - Education Excellence and Innovation Management through Vision 2020: From Regional Development Sustainability to Global Economic Growth, no. May, pp. 3815-3828, 2017.

[16] M. Kumar and R. Dwivedi, "Applicability of Scrum Methods in Software Development Process," SSRN Electronic Journal, 2020.

[17] V. Gomero-Fanny, A. R. Bengy, and L. Andrade-Arenas, "Prototype of web system for organizations dedicated to e-commerce under the scrum methodology," International Journal of Advanced Computer Science and Applications, vol. 12, no. 1, 2021. [Online]. Available: http://dx.doi.org/10.14569/IJACSA.2021.0120152

[18] A. Tupia-Astoray and L. Andrade-Arenas, "Implementation of an e-commerce system for the automation and improvement of commercial management at a business level," International Journal of Advanced Computer Science and Applications, vol. 12, no. 1, 2021. [Online]. Available: http://dx.doi.org/10.14569/IJACSA.2021.0120177

[19] M. Morandini, T. A. Coleti, E. Oliveira, and P. L. P. Corrêa, "Considerations about the efficiency and sufficiency of the utilization of the Scrum methodology: A survey for analyzing results for development teams," Computer Science Review, vol. 39, p. 100314, feb 2021.

[20] B. Singh, "Comparative Study and Analysis of Scrum and Lean Methodology," International Journal for Research in Applied Science and Engineering Technology, vol. 6, no. 3, pp. 3441-3448, 2018.

[21] P. C. Van Oorschot, "Toward Unseating the Unsafe C Programming Language," IEEE Security and Privacy, vol. 19, no. 2, pp. 4-6, 2021.

[22] J. Yang and Z. Zhao, "Development and implementation of computer assisted instruction system in physical education based on ASP.NET Technology," International Journal of Emerging Technologies in Learning, vol. 14, no. 13, pp. 145-156, 2019.

[23] A. Fedorov and A. Lukyanchikov, Recent Achievements and Prospects of Innovations and Technologies, 2019.

[24] Mubassiran, "Jurnal Ilmiah Manajemen Informatika," Ilmiah Manajemen Informatika, vol. 12 , no. 2, pp. 1-70, 2020

[25] A. Carrion-Silva, C. Diaz-Nunez, and L. Andrade-Arenas, "Admission exam web application prototype for blind people at the university of sciences and humanities," International Journal of Advanced Computer Science and Applications, vol. 11, no. 12, 2020. [Online]. Available: http://dx.doi.org/10.14569/IJACSA.2020.0111246

[26] L. R. Tuanama, J. Q. Gutarra, and L. Andrade-Arenas, "Design of a mobile application for the automation of the census process in peru," International Journal of Advanced Computer Science and Applications, vol. 11, no. 11, 2020. [Online]. Available: http://dx.doi.org/10.14569/IJACSA.2020.0111184

[27] INEI, "La anemia en el perú," 2018. [Online]. Available: https://proyectos.inei.gob.pe/endes/resultados.asp 